\title{
Three-dimensional model evaluation of the Ozone Depletion Potentials for n-propyl bromide, trichloroethylene and perchloroethylene
}

\author{
D. J. Wuebbles ${ }^{1}$, K. O. Patten ${ }^{1}$, D. Wang ${ }^{1}$, D. Youn ${ }^{2}$, M. Martínez-Avilés ${ }^{3, *}$, and J. S. Francisco ${ }^{3}$ \\ ${ }^{1}$ Department of Atmospheric Sciences, University of Illinois at Urbana-Champaign, Urbana, IL, USA \\ ${ }^{2}$ School of Earth and Environmental Sciences Seoul National University Seoul, Seoul, South Korea \\ ${ }^{3}$ Department of Chemistry and Department of Earth and Atmospheric Sciences, Purdue University, West Lafayette, IN, USA \\ *now at: National Institute of Water and Atmospheric Research Omakau, Central Otago, New Zealand
}

Received: 1 June 2010 - Published in Atmos. Chem. Phys. Discuss.: 26 July 2010

Revised: 18 February 2011 - Accepted: 23 February 2011 - Published: 15 March 2011

\begin{abstract}
The existing solvents trichloroethylene (TCE) and perchloroethylene (PCE) and proposed solvent n-propyl bromide (nPB) have atmospheric lifetimes from days to a few months, but contain chlorine or bromine that could affect stratospheric ozone. Several previous studies estimated the Ozone Depletion Potentials (ODPs) for various assumptions of nPB emissions location, but these studies used simplified modeling treatments. The primary purpose of this study is to reevaluate the ODP for n-propyl bromide (nPB) using a current-generation chemistry-transport model of the troposphere and stratosphere. For the first time, ODPs for TCE and PCE are also evaluated in a three-dimensional, global atmospheric chemistry-transport model. Emissions representing industrial use of each compound are incorporated on land surfaces from $30^{\circ} \mathrm{N}$ to $60^{\circ} \mathrm{N}$. The atmospheric chemical lifetime obtained for nPB is 24.7 days, similar to past literature, but the ODP is 0.0049 , lower than in our past study of nPB. The derived atmospheric lifetime for TCE is 13.0 days and for PCE is 111 days. The corresponding ODPs are 0.00037 and 0.0050 , respectively.
\end{abstract}

\section{Introduction}

n-propyl bromide (chemical formula $\mathrm{CH}_{3} \mathrm{CH}_{2} \mathrm{CH}_{2} \mathrm{Br}$, also named 1-bromopropane and abbreviated below as nPB) has been proposed as a potential replacement for compounds that have been used as solvents for many years including

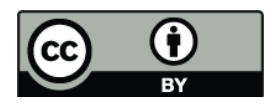

Correspondence to: D. J. Wuebbles (wuebbles@atmos.uiuc.edu) trichloroethylene (TCE, chemical formula $\mathrm{C}_{2} \mathrm{HCl}_{3}$ ) and perchloroethylene (PCE, chemical formula $\mathrm{C}_{2} \mathrm{Cl}_{4}$, also named tetrachloroethylene). TCE is widely used as an industrial solvent; PCE is commonly used in fabrics dry-cleaning, metal degreasing, as well as a feedstock for chemical manufacture. As discussed in the 2002 World Meteorological Organization international stratospheric ozone assessment (Ko et al., 2003), four modeling studies (Wuebbles et al., 1999, 2001; Bridgeman et al., 2000; Olsen et al., 2000) have previously evaluated Ozone Depletion Potentials (ODPs) for nPB. These studies used the modified concept for ODPs that accounts for the location of emissions (Wuebbles and Ko, 1999) as compared to the original definition developed for longer-lived gases. However, none of the nPB studies evaluated the ODPs using a three-dimensional chemistry-transport model of the troposphere and stratosphere with complete representation of relevant chemistry processes. The purpose of this study is to update the ODPs for nPB using such a model. In addition, ODPs of TCE and PCE are evaluated, though the primary environmental concerns about these compounds relate to their toxicity, as summarized in OEHHA (1999, 2000).

In the earlier nPB studies, Wuebbles et al. (1999) used a zonally-averaged two-dimensional (2-D) model to estimate the ODP. Olsen et al. (2000) applied the low-resolution $\left(8^{\circ}\right.$ latitude $\times 10^{\circ}$ longitude $\times 9$ layers) three-dimensional (3-D) UCI tropospheric chemical-transport model to determine the amount of very short-lived (VSL) substances for a range of atmospheric lifetimes, and for various seasons and latitudes of emission, reaching the tropical tropopause. Then by scaling the ODP values from 2-D model results (Wuebbles et al., 1999), they estimated ODP values for nPB ranging

Published by Copernicus Publications on behalf of the European Geosciences Union. 
from 0.0002 (for summer emissions at $56^{\circ} \mathrm{N}$ to $64^{\circ} \mathrm{N}$ ) to as large as 0.06 for tropical emissions. Bridgeman et al. (2000) used the TOMCAT 3-D global chemical-transport model $\left(5.6^{\circ} \times 5.6^{\circ} \times 31\right.$ levels $)$ to evaluate the atmospheric lifetime and amount of nPB reaching the stratosphere as a function of location and season of emission. They calculated ODPs empirically, based on the derived lifetime and the fraction of $\mathrm{nPB}$ emissions reaching the stratosphere. For nPB, they derived ODPs that vary from 0.0033 for emissions from Europe to 0.0109 for emissions from Indonesia. The study assumed that any bromine atoms released in the troposphere would be removed by rainout with $100 \%$ efficiency before reaching the stratosphere. Thus, their derived ODPs only considered the direct $\mathrm{nPB}$ reaching the stratosphere.

Wuebbles et al. (2001) used the MOZART-2 3-D chemical-transport model $\left(5^{\circ} \times 5^{\circ} \times 34\right.$ levels $)$ in combination with studies using their 2-D model in examining the potential effects of nPB on stratospheric ozone and the corresponding set of ODPs for nPB, and attempted to quantify degradation product effects. With available information, bromoacetone was the intermediate degradation product which had the largest concentration and had a local photochemical lifetime more than 1 day. For nPB emitted equally over global land masses north of $60^{\circ} \mathrm{S}$ and south of $70^{\circ} \mathrm{N}$, their 3-D model calculations suggest that about $0.44 \%$ of the emitted bromine enters the stratosphere. About $33 \%$ of the bromine reaching the stratosphere results from the direct transport of nPB to the stratosphere and about $19 \%$ due to the transport of bromoacetone to the stratosphere. The rest $(48 \%)$ is from transport of inorganic bromine.

These studies indicated the potential importance of considering both pathways in deriving the halogen reaching the stratosphere and the resulting ODPs for VSL gases like nPB. However, measurements by Burkholder et al. (2002) suggest that the local lifetime of bromoacetone is a few hours rather than at least one day as assumed in Wuebbles et al. (2001). Ko et al. (2003) modified the Wuebbles et al. (2001) ODP values to account for this overestimate of the bromoacetone atmospheric lifetime. For nPB emissions at midlatitudes (North America, Europe, and Asia - roughly $30^{\circ} \mathrm{N}$ to $60^{\circ} \mathrm{N}$ ), the modified ODPs range from 0.017 to 0.026 .

Since the earlier studies were published, much more has been learned about the oxidation of nPB and the chemistry of $\mathrm{nPB}$ degradation products in the atmosphere. In addition to the Burkholder et al. (2002) study of bromoacetone, there have been new measurements and analyses of nPB reaction with OH (Gilles et al., 2002; Martínez-Avilés et al., 2008a) and of the specific reactions and reaction rates in the reaction mechanism after initiation (Martínez-Avilés et al., 2008b). We have incorporated these new findings into the reaction mechanism used in the modeling studies.

\section{Methodology}

The ODP concept (Wuebbles, 1981, 1983) arose as a means of determining the relative ability of a chemical to destroy stratospheric ozone. ODPs are an integral part of national and international considerations on ozone-protection policy, including the Montreal Protocol and its Amendments and the US Clean Air Act. ODPs provide an important and relatively straightforward way of analyzing the potential for a new chemical to affect ozone relative to the CFCs, Halons, and other replacement compounds. ODPs are currently determined by two different means: calculations from chemistrytransport models of the global atmosphere (CTMs), and calculations using a semi-empirical approach (Solomon et al., 1992).

An ODP is a relative measure of the expected cumulative effect on stratospheric ozone per unit mass emission of a gas compared with the expected effect from the same mass emission of CFC-11. Therefore, it is defined as the change in total ozone per unit mass emission of the gas, relative to the change in total ozone per unit mass emission of CFC- 11 . ODP by itself does not, however, indicate the actual emissions or the amount of ozone depletion that has occurred or might occur.

Traditionally, zonally averaged 2-D CTMs were used for calculating the ozone response in the stratosphere. Past ODP evaluations were conducted for chemicals with atmospheric lifetimes more than approximately one year. Such long-lived gases mixed well throughout the troposphere after surface release, and large fractions of the surface emissions reached the stratosphere. However, many of the compounds now being considered either for new applications or as replacements for substances controlled under the Montreal Protocol are designed to be short-lived, on the order of days to a few months, so as to reduce the impacts on ozone and climate. These short-lived replacement gases still can be vertically transported into the lower stratosphere by intense convection in the tropical troposphere, which is relevant to possible effects on ozone from these compounds. Thus, the ODP of a VSL species depends upon its distribution in the atmosphere and the location of its source (Wuebbles and Ko, 1999; Wuebbles et al., 2001; Ko et al., 2003). Unfortunately, the determination of ODPs for these gases is not straightforward because their short atmospheric lifetimes leave them poorly mixed in the troposphere. Because they lose halogens in the troposphere, VSLSs can also cause $\mathrm{O}_{3}$ depletion in the troposphere, where both $\mathrm{O}_{3}$ precursors and loss processes are highly variable with longitude and thus not easily treated in the zonal average. Also, the traditional 2-D model analysis of ODPs is not sufficiently accurate to calculate the integrated amount of the halogenated VSL source and reaction product gases in the troposphere that enter the stratosphere (Wuebbles et al., 2001).

3-D CTMs representing the complete troposphere and stratosphere are necessary for evaluating the halogen loading 
and ozone depletion for VSL species. Thus the definition of ODPs has been revised for VSL compounds (Wuebbles et al., 2001; Ko et al., 2003). The new ODP definition for the VSL compounds accounts for the variation that can occur in the ODP as a function of where and when the compound is used and emitted. The most important factor in evaluating the ODP of VSL compounds is shown to be latitude distribution of the surface emissions because halogens from source gases emitted at higher latitudes are less likely to reach the stratosphere than from source gases emitted in the tropics (Bridgeman et al., 2000; Olsen et al., 2000; Wuebbles et al., 2001). 3-D CTMs, which include a much more comprehensive treatment of transport than available for 2-D models, are now preferable for calculations of ODPs both for the longer-lived gases and for the very short-lived candidate replacement compounds. These models can not only determine the amount of the substance reaching the stratosphere directly but can also follow the processes affecting the reaction products. Studies suggest that most chlorine or bromine that reaches the stratosphere from VSL substances is transported there in reaction products (Wuebbles et al., 2001; Ko et al., 2003; Law et al., 2007).

\subsection{Atmospheric model}

This study uses the current-generation 3-D model of global atmospheric chemistry and physics developed by the $\mathrm{Na}-$ tional Center for Atmospheric Research (NCAR) called the Model for OZone And Related Tracers version 3.1 (MOZART-3). MOZART-3 has been used to explicitly calculate the impact of halocarbon emissions added at the Earth surface into the atmosphere on ozone depletion. The MOZART-3 CTM includes a complete representation of tropospheric, stratospheric, and upper atmospheric processes (Kinnison et al., 2007). It incorporates a full stratosphere, including the chemistry of chlorine species $\left(\mathrm{Cl}_{\mathrm{y}}\right)$ and bromine species $\left(\mathrm{Br}_{\mathrm{y}}\right)$ important in stratospheric ozone calculation as well as updated hydrogen, nitrogen, and hydrocarbon oxidation chemistry relevant to stratospheric and tropospheric chemistry included in the lower atmospheric version, MOZART-2 (Horowitz et al., 2003). The water-soluble $\mathrm{Cl}_{\mathrm{y}}$ species $\mathrm{HCl}, \mathrm{HOCl}$, and $\mathrm{ClONO}_{2}$ and the water-soluble $\mathrm{Br}_{\mathrm{y}}$ species $\mathrm{HBr}, \mathrm{HOBr}$, and $\mathrm{BrONO}_{2}$ are removed from the MOZART-3 atmosphere by tropospheric wet deposition with the same rate constant as used for $\mathrm{HNO}_{3}$. Representations of relevant heterogeneous and physical processes for winter/spring polar vortex related to ozone destruction are also fully included in the model. This model has been evaluated extensively via comparisons with measurements of atmospheric trace gases from satellite data and measurement campaigns (e.g., Wei et al., 2003; Pan et al., 2007).

Chemical reaction-rate constants and photochemical data for reactions other than those of $\mathrm{nPB}$, its degradation product bromoacetone, TCE, and PCE follow the recommendations of Sander et al. (2003). The MOZART-3 CTM is driven by meteorology fields derived from the Whole Atmosphere Community Climate Model (WACCM) version 1b (Sassi et al., 2004). MOZART-3 thus has a $2.8^{\circ}$ resolution in latitude and longitude and a hybrid sigma-pressure vertical coordinate including 66 layers from the surface to $5.1 \times 10^{-6} \mathrm{hPa}$ (approximately $140 \mathrm{~km}$ ).

\subsection{Atmospheric oxidation of $\mathrm{nPB}$, TCE, and PCE}

In this study, the initiating reaction of $\mathrm{nPB}$ with $\mathrm{OH}$ radical is based on the rate constants from Gilles et al. (2002):

$k\left(\mathrm{nPB}+\mathrm{OH} \rightarrow \mathrm{CH}_{3} \mathrm{CH}_{2} \mathrm{CHBr}+\mathrm{H}_{2} \mathrm{O}\right)=1.44 \times 10^{-12} \exp (-450 / T)$
$k\left(\mathrm{nPB}+\mathrm{OH} \rightarrow \mathrm{CH}_{3} \mathrm{CHCH}_{2} \mathrm{Br}+\mathrm{H}_{2} \mathrm{O}\right)=2.54 \times 10^{-18} T^{2} \exp (265 / T)$
$k\left(\mathrm{nPB}+\mathrm{OH} \rightarrow \mathrm{CH}_{2} \mathrm{CH}_{2} \mathrm{CH}_{2} \mathrm{Br}+\mathrm{H}_{2} \mathrm{O}\right)=2.89 \times 10^{-12} \exp (-957 / T)$

where the temperature $T$ is in $\mathrm{K}$ and rate constants $k$ are in $\mathrm{cm}^{3}$ molec ${ }^{-1} \mathrm{~s}^{-1}$. Analysis of the subsequent reactions by the radicals produced by $\mathrm{OH}$ reaction with $\mathrm{nPB}$ from Martínez-Avilés et al. (2008a, b) suggests that the only organobromine degradation product to have a significant lifetime against further reaction and to be produced in a significant fraction of the nPB input to the atmosphere is bromoacetone, $\mathrm{CH}_{3} \mathrm{C}(\mathrm{O}) \mathrm{CH}_{2} \mathrm{Br}$ (abbreviated as $\mathrm{BrAc}$ below). The absorption cross sections and photolysis quantum yields for BrAc of Burkholder et al. (2002) are used in this study.

The chloroalkenes PCE and TCE are expected to react in the atmosphere primarily by addition of $\mathrm{OH}$ radical to the $\mathrm{C}=\mathrm{C}$ double bond. The rate constants for these addition reactions are taken as the high-pressure limit expressions from the JPL 2006 photochemical data evaluation by Sander et al. (2006):

$$
\begin{aligned}
& k(\mathrm{PCE}+\mathrm{OH})=4.7 \times 10^{-12} \exp (-990 / T) \\
& k(\mathrm{TCE}+\mathrm{OH})=8.00 \times 10^{-13} \exp (300 / T)
\end{aligned}
$$

where the temperature $T$ is in $\mathrm{K}$ and rate constants $k$ are in $\mathrm{cm}^{3}$ molec $^{-1} \mathrm{~s}^{-1}$. The $\mathrm{PCE}+\mathrm{OH}$ rate constant expression in the IUPAC photochemical data evaluation (Atkinson et al., 2008) agrees with that in Sander et al. (2006) to within $6 \%$ for $T$ of 200 to $300 \mathrm{~K}$. The TCE $+\mathrm{OH}$ rate constant expression from Atkinson et al. (2008) agrees with that given by Sander et al. (2006) for $T$ of 240 to $300 \mathrm{~K}$; while the IUPAC values are more than $10 \%$ higher for $\mathrm{T}$ below $240 \mathrm{~K}$, this is not expected to produce much difference in the TCE lifetime because limited amounts of TCE reach colder temperatures in the upper troposphere (see Fig. 4a below).

Radicals produced by $\mathrm{OH}$ addition to PCE or TCE then are likely to add $\mathrm{O}_{2}$, then react with $\mathrm{NO}$ to produce chlorinated hydroxyalkoxy radicals. In this study, we have approximated the subsequent chemistry as release of all chlorine within one time step. The chlorinated hydroxyalkoxy radicals are likely to produce phosgene $\left(\mathrm{CCl}_{2} \mathrm{O}\right)$ for both TCE and PCE and chloroformaldehyde $(\mathrm{CHClO})$ for $\mathrm{TCE}$, which react further by both $\mathrm{OH}$ and photolysis under daytime conditions suitable for oxidation of PCE or TCE. 


\subsection{ODP from MOZART-3}

We evaluate the atmospheric lifetimes and Ozone Depletion Potentials (ODPs) for the three compounds in the MOZART3 CTM. A steady-state background atmosphere corresponding to the year 2000 was derived assuming fixed surface mixing ratios for long-lived gases (such as nitrous oxide, methane, chlorofluorocarbons, and other halogenated source gases) and fixed emissions for short-lived gases. An ODP calculation in an atmospheric CTM requires two perturbation runs for comparison to the CTM reference atmosphere: a CFC-11 $\left(\mathrm{CFCl}_{3}\right.$, also known as trichlorofluoromethane) run and a run incorporating the compound under evaluation. The perturbations of CFC-11 or of the compound under evaluation are selected to give similar decreases in globallyaveraged $\mathrm{O}_{3}$ that are less than one percent. Emissions of $\mathrm{nPB}, \mathrm{TCE}$, and PCE were assumed to occur entirely on land at midlatitudes in the Northern Hemisphere, from $30^{\circ} \mathrm{N}$ to $60^{\circ} \mathrm{N}$ (which corresponds to where the vast majority of current or future emissions are also expected to occur). In addition, for $\mathrm{nPB}$ the atmospheric lifetime and ODP was determined assuming emissions evenly distributed over land globally, from $60^{\circ} \mathrm{S}$ to $70^{\circ} \mathrm{N}$. Each CTM perturbation is run to steady state, after which the change in total $\mathrm{O}_{3}$ burden in the atmosphere and the flux of the substance causing the ozone change are calculated for the CFC-11 run and for the run of the compound under study. The ODPs calculated in this study use the global total $\mathrm{O}_{3}$ burden loss because $\mathrm{O}_{3}$ absorbs harmful solar ultraviolet radiation whether or not it is located in the stratosphere; we do not attempt to separate ODP into tropospheric and stratospheric components, though we do note the fraction of $\mathrm{O}_{3}$ burden loss that occurs in the troposphere for $\mathrm{nPB}$, TCE, and PCE below.

The CFC-11 perturbation used in MOZART-3 for this study is an increase of the fixed surface mixing ratio by $80 \mathrm{ppt}$. This perturbation required 10 years of model time to reach a steady state global $\mathrm{O}_{3}$ burden loss of $-0.594 \%$. The change in CFC-11 loss rate due to that perturbation is $0.0335 \mathrm{Tg} \mathrm{yr}^{-1}$, which equals the increase of CFC-11 flux at the surface in the model. nPB, TCE, and PCE fluxes added to the model in this study are chosen to provide global $\mathrm{O}_{3}$ burden losses less than $1 \%$ and similar, ideally to within a factor of two, to $0.594 \%$ as obtained for CFC- 11 ; these fluxes are not intended to represent historic, current, or likely future emissions of any of these compounds. We ran all of the model calculations on the same compute platform in order to avoid possible portability issues.

\section{Results}

This study considers three VSLSs with a variety of surface fluxes introduced into the MOZART-3 CTM and a significant range of atmospheric lifetimes. In order to enable comparison among these results, we sought to present them on a common basis in the figures that follow. ODP is a measure of relative decrease in global $\mathrm{O}_{3}$ burden, so that we select $1 \%$ decrease in global $\mathrm{O}_{3}$ burden arising from each VSLS scenario as that common basis. Because the $\mathrm{O}_{3}$ burden loss is expected to be proportional to the flux of each VSLS and to the increase in $\mathrm{Cl}_{\mathrm{y}}$ or $\mathrm{Br}_{\mathrm{y}}$ resulting from addition of that VSLS to MOZART-3, we divide each model output (annualand zonal-average VSLS mixing ratios, $\mathrm{Cl}_{\mathrm{y}}$ or $\mathrm{Br}_{\mathrm{y}}$ mixing ratio perturbations, percent changes in $\mathrm{O}_{3}$ mixing ratio, and $\mathrm{BrAc}$ mixing ratios for $\mathrm{nPB}$ as the VSLS) presented in the figures below by the total global $\mathrm{O}_{3}$ burden loss averaged over the year for that VSLS as calculated in MOZART-3. We refer to these values from MOZART- 3 divided by global $\mathrm{O}_{3}$ burden loss by the phrase "per $1 \% \mathrm{O}_{3}$ burden loss" in this discussion.

\section{1 nPB}

The nPB flux used to illustrate industrial use is a rate of $8.64 \times 10^{8}$ molecules $\mathrm{cm}^{-2} \mathrm{~s}^{-1}$ from all land at latitudes $30^{\circ} \mathrm{N}$ to $60^{\circ} \mathrm{N}$, for a total $\mathrm{nPB}$ emission rate of $2.48 \mathrm{Tg} \mathrm{yr}^{-1}$. That flux required 7 model years to reach steady state and resulted in a global $\mathrm{O}_{3}$ burden decrease of $0.214 \%$, of which $0.123 \%$ was above the tropopause. Figure 1 shows the derived annual and zonal average distribution of $\mathrm{nPB}$, the corresponding distribution of $\mathrm{BrAc}$ and change in $\mathrm{Br}_{\mathrm{y}}$, and the resulting change in the distribution of tropospheric and stratospheric $\mathrm{O}_{3}$ divided by the $0.214 \%$ decrease in global $\mathrm{O}_{3}$ burden. In each part of this and subsequent figures, the dotted white line indicates the average pressure level of the MOZART tropopause. The nPB mixing ratio per $1 \% \mathrm{O}_{3}$ burden loss in Fig. 1a peaks at the emissions region with little reaching the Southern Hemisphere, and no more than $10 \mathrm{ppt}$, or $2 \%$ of the $349 \mathrm{ppt}$ maximum mixing ratio, reaches the tropopause. The potential product gas injection $\mathrm{BrAc}$ mixing ratio per $1 \% \mathrm{O}_{3}$ burden loss peaks at $2.1 \mathrm{ppt}$ near the surface in Fig. 1b, and its maximum mixing ratio at the tropopause is less than 0.02 ppt. However, the $\mathrm{Br}_{\mathrm{y}}$ perturbation per $1 \% \mathrm{O}_{3}$ burden loss in the Northern Hemisphere exceeds $2.5 \mathrm{ppt}$ for much of the lower stratosphere, as shown in Fig. 1c. The stratospheric $\mathrm{Br}_{\mathrm{y}}$ perturbation in excess of nPB mixing ratios at the tropopause suggests that $\mathrm{Br}_{\mathrm{y}}$ in the stratosphere is increased by some means besides the $\mathrm{nPB}$ that reaches the stratosphere. The minimum $\mathrm{Br}_{\mathrm{y}}$ perturbation in the tropics suggests that the remainder of the stratospheric $\mathrm{Br}_{\mathrm{y}}$ perturbation could be due to a decrease in the net $\mathrm{Br}_{\mathrm{y}}$ transport from the stratosphere to the troposphere caused by the $\mathrm{Br}_{\mathrm{y}}$ increase in the Northern troposphere. nPB increases $\mathrm{Br}_{\mathrm{y}}$ by at least $1 \mathrm{ppt}$ everywhere in and above the MOZART stratosphere, and the $\mathrm{O}_{3}$ perturbation percentage per $1 \% \mathrm{O}_{3}$ burden loss in Fig. 1d includes both a peak in the Northern polar upper troposphere and a secondary maximum near the South Polar tropopause with minimal $\mathrm{O}_{3}$ loss in the tropics around $10 \mathrm{hPa}$. The atmospheric chemical lifetime obtained 

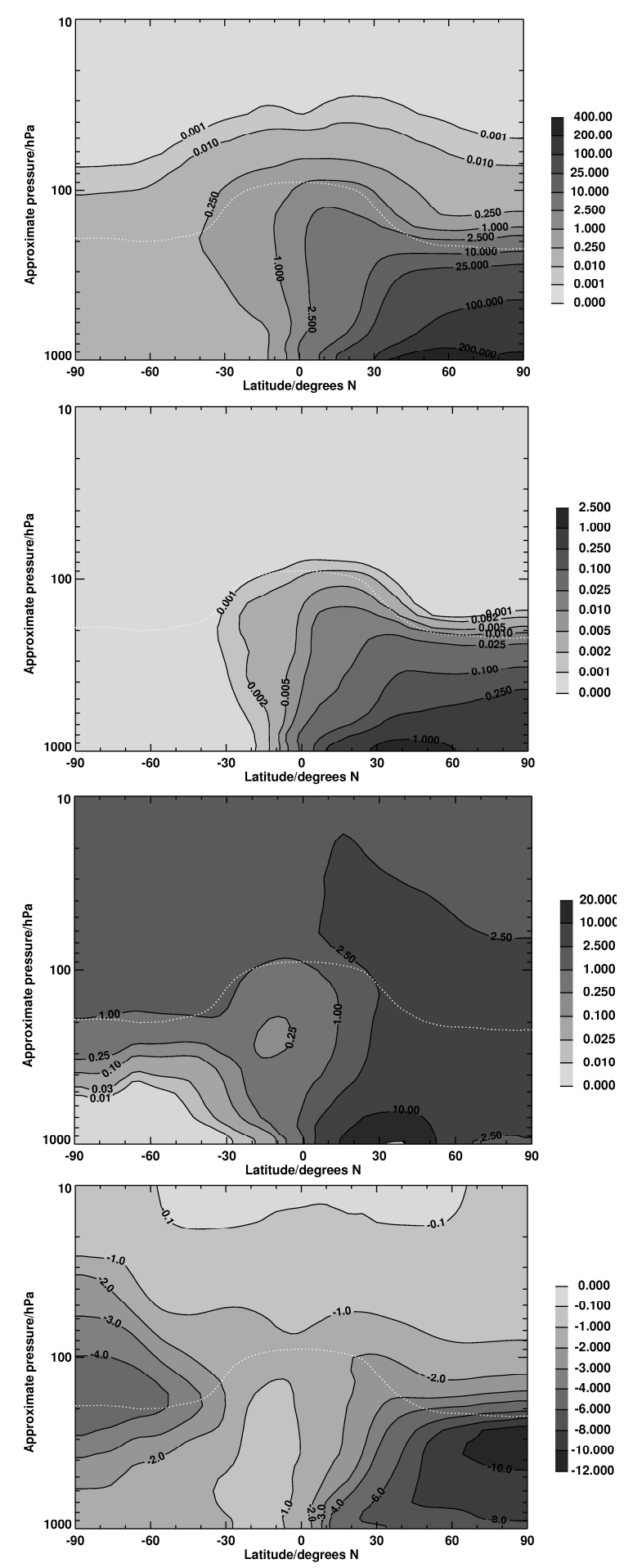

Fig. 1. Annual- and zonal-average mixing ratio changes calculated in MOZART-3 for n-propyl bromide (nPB) emissions evenly distributed on land surfaces from $30^{\circ} \mathrm{N}$ to $60^{\circ} \mathrm{N}$ totaling $2.48 \mathrm{Tg} \mathrm{yr}^{-1}$, divided by 0.214 to correspond to $1 \%$ decrease in global total ozone $\left(\mathrm{O}_{3}\right)$ burden. (a) nPB in ppt; (b) bromoacetone (BrAc) in ppt; (c) inorganic bromine species $\left(\mathrm{Br}_{\mathrm{y}}\right)$ in ppt; (d) $\mathrm{O}_{3}$ in percent. In this and all following figures, the dotted white line represents the annualand zonal-average tropopause.

for $\mathrm{nPB}$ is 24.7 days, comparable to the value reported in Ko et al. (2003), and the chemical lifetime for $\mathrm{BrAc}$ is $5.4 \mathrm{~h}$, consistent with the estimate of Burkholder et al. (2002). The ODP obtained for nPB is 0.0049 , smaller than the value reported previously. This ODP is lower by a factor of more than three compared to the most comparable value reported in Tables 2-12 of Ko et al. (2003), 0.017 for emissions from North America, Europe, and Asia with the correction for reduced $\mathrm{BrAc}$ using maximum rainout of $\mathrm{Br}_{\mathrm{y}}$ species in Wuebbles et al. (2001). Atmospheric lifetimes and ODPs for nPB, TCE, and PCE obtained in this study are summarized in Table 1 .

A study with $\mathrm{nPB}$ emissions of $2.90 \times 10^{8}$ molecules $\mathrm{cm}^{-2}$ $\mathrm{s}^{-1}$ evenly distributed over land surfaces from $60^{\circ} \mathrm{S}$ to $70^{\circ} \mathrm{N}$, which totals $2.49 \mathrm{Tg} \mathrm{yr}^{-1}$ and is comparable to the "global" case in Wuebbles et al. (2001), was also conducted in MOZART-3; this perturbation also required 7 model years to reach steady state with a global $\mathrm{O}_{3}$ column change of $-0.470 \%$. The nPB annual and zonal average mixing ratios divided by 0.470 to represent $1 \%$ global $\mathrm{O}_{3}$ burden loss, shown in Fig. 2a, show that penetration to the tropopause is more symmetric than for $30^{\circ}-60^{\circ} \mathrm{N}$ emissions, and between 1 and $2.5 \mathrm{ppt}$ of $\mathrm{nPB}$ reaches the tropopause at all latitudes north of $25^{\circ} \mathrm{S}$. While the BrAc distribution per $1 \% \mathrm{O}_{3}$ burden loss in Fig. $2 \mathrm{~b}$ is also more symmetric than that for $30^{\circ}-60^{\circ} \mathrm{N} \mathrm{nPB}$ emissions, the peak mixing ratio is $0.43 \mathrm{ppt}$ compared to a maximum $\mathrm{nPB}$ mixing ratio of $110 \mathrm{ppt}$ in Fig. 2a, and the maximum tropopause BrAc mixing ratio is less than 0.005 ppt. The $\mathrm{Br}_{\mathrm{y}}$ perturbation per $1 \% \mathrm{O}_{3}$ burden loss from these nPB emissions, shown in Fig. 2c, is more than $2.5 \mathrm{ppt}$ throughout much of the stratosphere up to the 10 $\mathrm{hPa}$ pressure layer, but the $\mathrm{Br}_{\mathrm{y}}$ perturbation at the tropopause is smaller for $30^{\circ} \mathrm{S}$ to $30^{\circ} \mathrm{N}$ than for surrounding latitudes outside that range. As with Fig. 1a-c, the fact that stratospheric $\mathrm{Br}_{\mathrm{y}}$ increases more than the maximum stratospheric $\mathrm{nPB}$ mixing ratio indicates that in addition to the component from $\mathrm{nPB}$ reaching the stratosphere, stratospheric $\mathrm{Br}_{\mathrm{y}}$ from $n P B$ in MOZART-3 could be increasing in part because of decreased net $\mathrm{Br}_{\mathrm{y}}$ transport from the stratosphere to the troposphere resulting from increased $\mathrm{Br}_{\mathrm{y}}$ concentrations in the extratropical troposphere. The $\mathrm{O}_{3}$ percent loss profile per $1 \%$ $\mathrm{O}_{3}$ burden loss from these nPB emissions shown in Fig. 2d again peaks at either pole, but the South Polar tropopause is the maximum loss and the reduction in tropical tropospheric $\mathrm{O}_{3}$ is greater than for $30^{\circ}-60^{\circ} \mathrm{N}$ emissions in Fig. $1 \mathrm{~d}$. For the global emissions case, the derived atmospheric lifetime of nPB is 19.6 days, nearly the same as in Wuebbles et al. (2001), and the resulting ODP is 0.011 , more than a factor of two lower than the global high wet-deposition ODP reported in Wuebbles et al. (2001) or the 0.027 value given in Ko et al. (2003) Table 2-12 for that Wuebbles et al. (2001) result after correction for the revised BrAc lifetime. The comparisons of current ODPs with the values reported in Ko et al. (2003) after $\mathrm{BrAc}$ lifetime correction indicate that $\mathrm{O}_{3}$ in MOZART-3 is less sensitive to $\mathrm{Br}_{\mathrm{y}}$ from nPB than was the 
Table 1. Derived atmospheric lifetimes and ODPs.

\begin{tabular}{llll}
\hline Gas & Emissions Latitudes & Lifetime, days & ODP \\
\hline $\mathrm{nPB}$ & $30^{\circ} \mathrm{N}-60^{\circ} \mathrm{N}$ & 24.7 & 0.0049 \\
$\mathrm{nPB}$ & $60^{\circ} \mathrm{S}-70^{\circ} \mathrm{N}$ & 19.6 & 0.011 \\
$\mathrm{TCE}$ & $30^{\circ} \mathrm{N}-60^{\circ} \mathrm{N}$ & 13.0 & 0.00037 \\
$\mathrm{PCE}$ & $30^{\circ} \mathrm{N}-60^{\circ} \mathrm{N}$ & 111 & 0.0050 \\
\hline
\end{tabular}

Table 2. Summary of lifetimes and ozone changes in MOZART-3 for two total surface fluxes of trichloroethylene (TCE) from $30^{\circ} \mathrm{N}$ to $60^{\circ} \mathrm{N}$ land surfaces.

\begin{tabular}{llll}
\hline TCE flux, $\mathrm{Tg} \mathrm{yr}^{-1}$ & Lifetime, days & $\mathrm{O}_{3}$ column change, \% & ODP \\
\hline 12.9 & 13.0 & -0.0851 & 0.00037 \\
51.7 & 13.8 & -0.338 & 0.00037 \\
\hline
\end{tabular}

case for the combination of MOZART-2 with the UIUC 2-D model as used in Wuebbles et al. (2001).

\subsection{PCE and TCE}

The MOZART-3 CTM with added surface flux for land from $30^{\circ} \mathrm{N}$ to $60^{\circ} \mathrm{N}$ is run to near-steady-state for TCE and for PCE as with nPB fluxes. After 9 years model time to reach steady state, a PCE surface flux of $3.91 \mathrm{Tg} \mathrm{yr}^{-1}$ in MOZART3 results in a global $\mathrm{O}_{3}$ column change of $-0.344 \%$. The annual and zonal average mixing ratio distribution due to PCE divided by 0.344 to represent $1 \%$ global $\mathrm{O}_{3}$ burden loss is shown in Fig. 3a. PCE reaches the tropical tropopause at a markedly higher fraction of the peak mixing ratio than for nPB (compare Fig. 1a). The tropopause PCE mixing ratios, which range from $100 \mathrm{ppt}$ at the North Pole to less than $50 \mathrm{ppt}$ poleward of $40^{\circ} \mathrm{S}$, are consistent with the stratospheric $\mathrm{Cl}_{\mathrm{y}}$ perturbation per $1 \% \mathrm{O}_{3}$ burden loss of up to $0.35 \mathrm{ppb}$ in Fig. $3 \mathrm{~b}$ because each PCE molecule carries four chlorine atoms and because the small values of tropospheric $\mathrm{Cl}_{\mathrm{y}}$ perturbation form a similar pattern to those from longerlived chlorocarbons such as HCFC-123. PCE seems likely to transport $\mathrm{Cl}_{\mathrm{y}}$ to the stratosphere as PCE by a combination of tropical and extra-tropical transport, unlike the case for $\mathrm{Br}_{\mathrm{y}}$ from nPB. Figure $3 \mathrm{c}$ shows that $\mathrm{O}_{3}$ loss from PCE per $1 \%$ $\mathrm{O}_{3}$ burden loss occurs mostly at polar latitudes with a maximum loss in the South Polar lower stratosphere. The PCE atmospheric lifetime obtained is 111 days, and the ODP calculated for PCE in MOZART is 0.0050, among the lowest of values obtained for any chlorocarbon so far.

TCE was run at two surface fluxes for which the MOZART results are summarized in Table 2. The initial run using $51.7 \mathrm{Tg} \mathrm{yr}^{-1}$ with 7 model years to reach steady state produced a global $\mathrm{O}_{3}$ column decrease of $0.338 \%$ with an atmospheric lifetime of 13.8 days. Figure 4 a shows the annual and
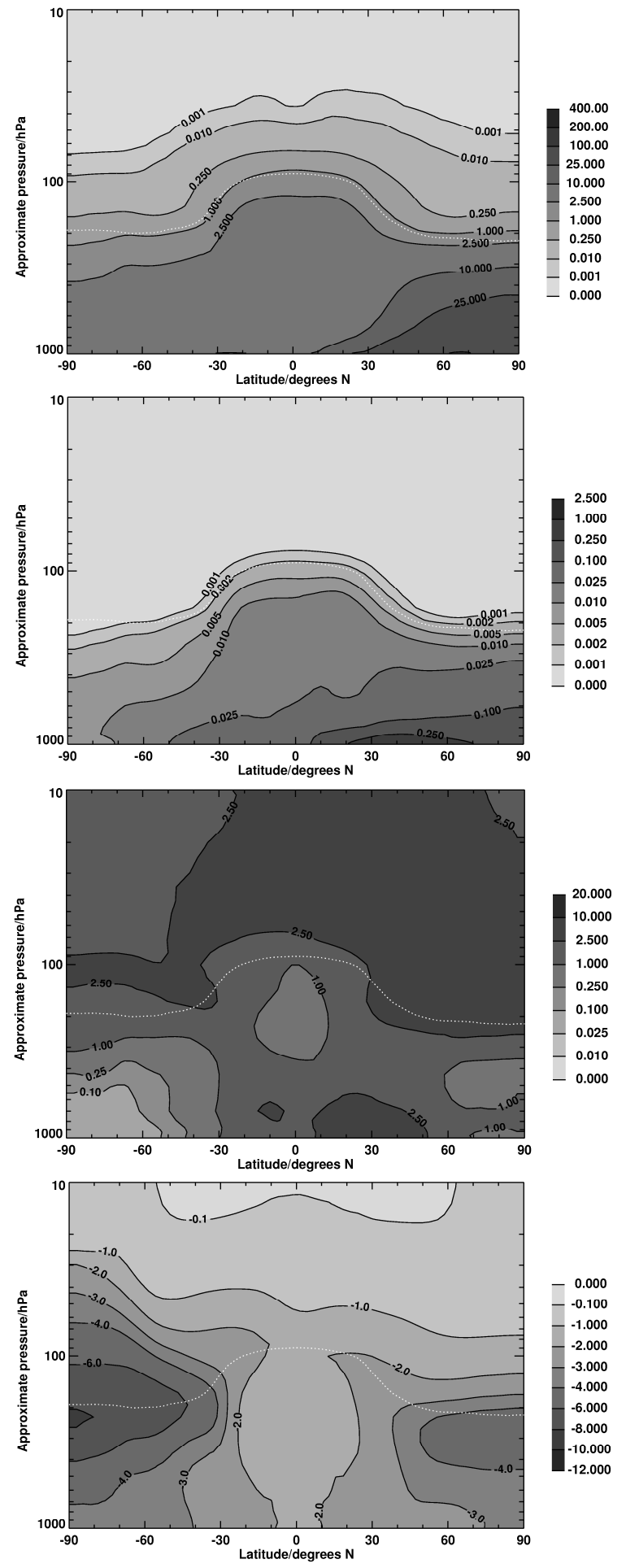

Fig. 2. Annual- and zonal-average mixing ratio changes calculated in MOZART-3 for nPB emissions evenly distributed on land surfaces from $60^{\circ} \mathrm{S}$ to $70^{\circ} \mathrm{N}$ totaling $2.49 \mathrm{Tg} \mathrm{yr}^{-1}$, divided by 0.470 to correspond to $1 \%$ decrease in global total $\mathrm{O}_{3}$ burden. (a) nPB in ppt; (b) BrAc in ppt; (c) $\mathrm{Br}_{\mathrm{y}}$ in ppt; (d) $\mathrm{O}_{3}$ in percent. 

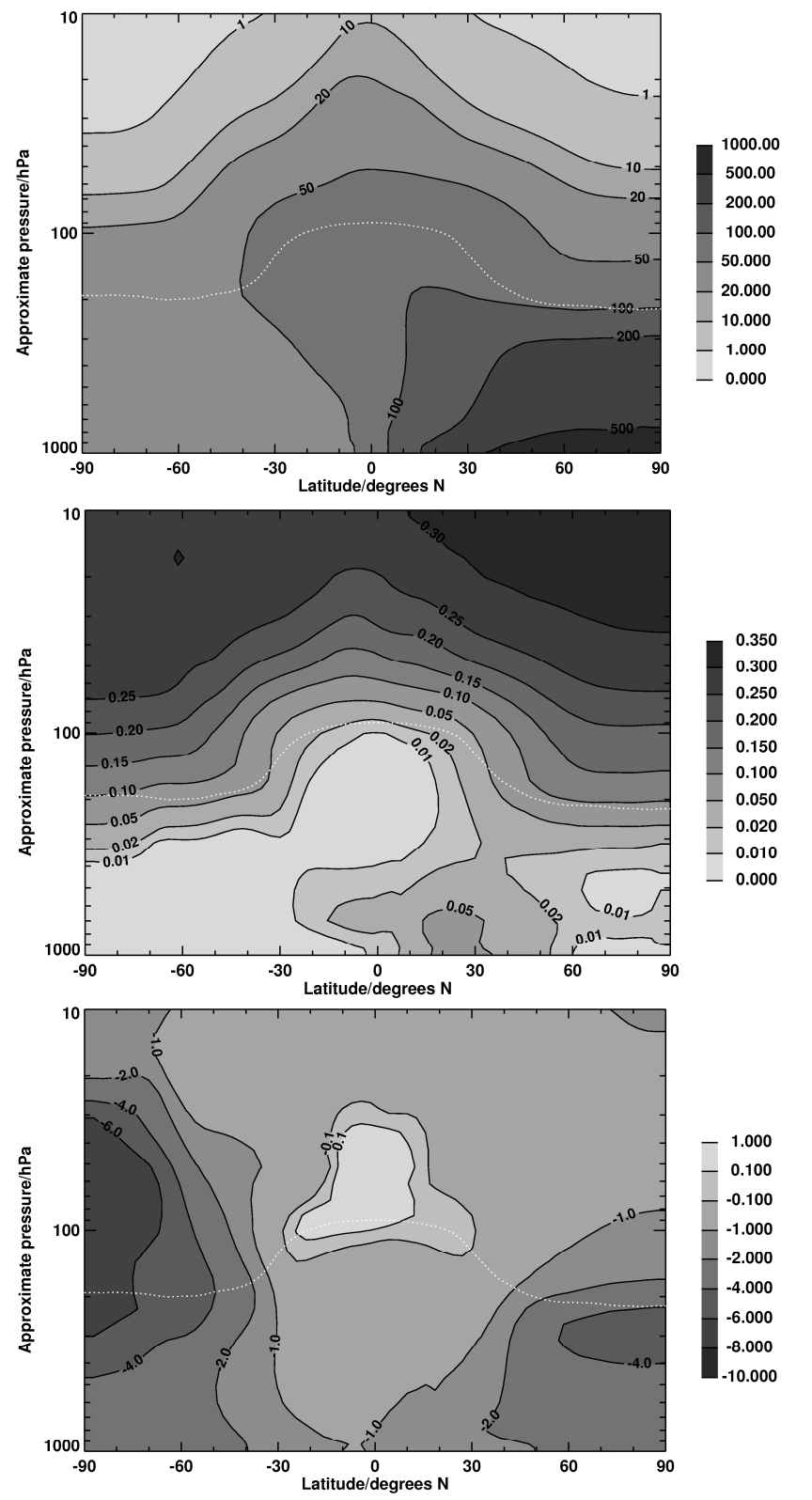

Fig. 3. Annual- and zonal-average mixing ratio changes calculated in MOZART-3 for perchloroethylene (PCE) emissions evenly distributed on land surfaces from $30^{\circ} \mathrm{N}$ to $60^{\circ} \mathrm{N}$ totaling $3.91 \mathrm{Tg} \mathrm{yr}^{-1}$, divided by 0.344 to correspond to $1 \%$ decrease in global total $\mathrm{O}_{3}$ burden. (a) PCE in ppt; (b) $\mathrm{Cl}_{\mathrm{y}}$ in ppb; (c) $\mathrm{O}_{3}$ in percent.

zonal average TCE distribution divided by 0.338 to represent a $1 \%$ global $\mathrm{O}_{3}$ burden loss. The maximum TCE mixing ratio per $1 \% \mathrm{O} 3$ burden loss is $5750 \mathrm{ppt}$ in the emissions region, and intact TCE transport to the stratosphere is limited to perhaps $0.1 \%$ even at the North Pole. The $\mathrm{Cl}_{\mathrm{y}}$ perturbations (ppb) per $1 \% \mathrm{O}_{3}$ burden loss in Fig. $4 \mathrm{~b}$ are concentrated in the emission region, with mixing of $\mathrm{Cl}_{\mathrm{y}}$ from TCE along the extratropical Northern upper troposphere and into the stratosphere seemingly limited by rainout removal at North Polar
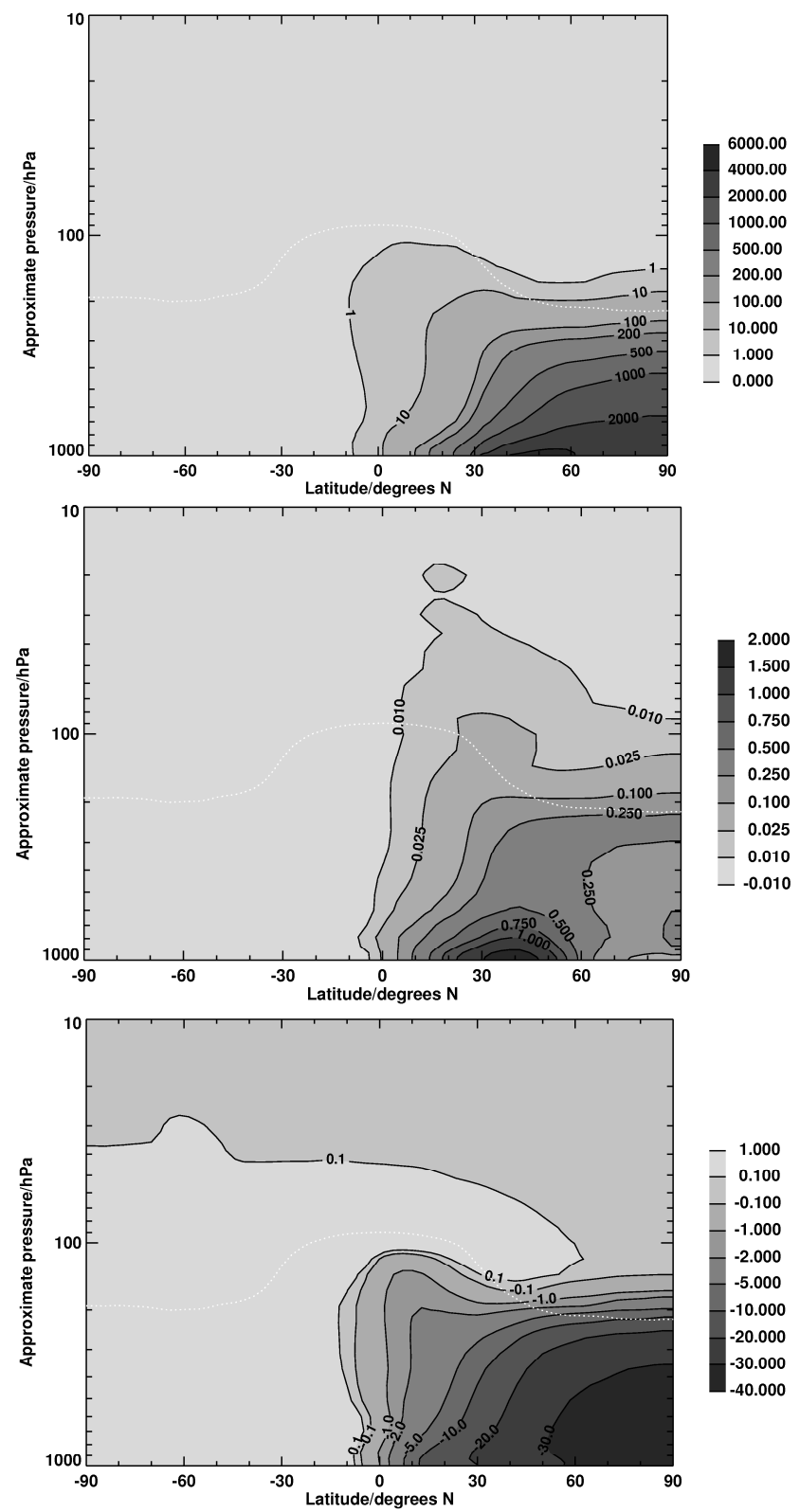

Fig. 4. Annual- and zonal-average mixing ratio changes calculated in MOZART-3 for trichloroethylene (TCE) emissions evenly distributed on land surfaces from $30^{\circ} \mathrm{N}$ to $60^{\circ} \mathrm{N}$ totaling $51.7 \mathrm{Tg} \mathrm{yr}^{-1}$, divided by 0.338 to correspond to $1 \%$ decrease in global total $\mathrm{O}_{3}$ burden. (a) TCE in ppt; (b) inorganic chlorine species $\left(\mathrm{Cl}_{\mathrm{y}}\right)$ in $\mathrm{ppb}$; (c) $\mathrm{O}_{3}$ in percent.

latitudes below the $300 \mathrm{hPa}$ pressure layer and effectively no change in $\mathrm{Cl}_{\mathrm{y}}$ throughout most of the stratosphere and the Southern troposphere. The $\mathrm{O}_{3}$ losses resulting from TCE per $1 \% \mathrm{O}_{3}$ burden loss shown in Fig. $4 \mathrm{c}$ are mostly constrained to the Northern troposphere and range up to $40 \%$ reduction. Because this large TCE flux results in such a large change of $\mathrm{O}_{3}$ at Northern latitudes, distortion of the $\mathrm{OH}$ field in MOZART resulting in an overestimation of TCE lifetime 
is a possible concern. Therefore, we also ran with one-fourth that TCE flux, or $12.9 \mathrm{Tg} \mathrm{yr}^{-1}$. After 8 model years to reach steady state (due to an operational problem in model year 7 of this run), the $\mathrm{O}_{3}$ column perturbation was one-fourth that of the $51.7 \mathrm{Tg} \mathrm{yr}^{-1}$ run, and the TCE lifetime reported was 13.0 days, consistent with a minimal $\mathrm{OH}$ field perturbation from TCE, and we report the lifetime from the $12.9 \mathrm{Tg} \mathrm{yr}^{-1}$ run in Table 1 . The TCE ODP, 0.00037 , is unaffected to within $1 \%$ by the change of surface flux.

The fluxes of TCE and PCE used in this study were selected in order to produce numerically significant $\mathrm{O}_{3}$ loss in MOZART-3, so that these fluxes are markedly larger than the global production of these compounds. The ODP results suggest that historic annual releases of these two chlorocarbons to the atmosphere, which as of 1999 totaled $0.146 \mathrm{Tg}$ for TCE and $0.387 \mathrm{Tg}$ for PCE in the Reactive Chlorine Emissions Inventory (McCulloch et al., 1999; Keene et al., 1999), should have less than $0.1 \%$ effects on global total ozone. Global emissions of TCE and PCE have been decreasing since 1999, and emissions of these compounds will likely continue to decrease in the future, so that these compounds likely produce negligible ozone effects.

Our MOZART-3 analyses of TCE and PCE have not considered possible degradation chemistry after the initial addition of $\mathrm{OH}$, instead treating these compounds as if all $\mathrm{Cl}$ atoms were released within a model time step. TCE and PCE atmospheric degradation schemes have not been comprehensively evaluated by experiment, but a recent study (Nolan et al., 2006) indicates that some $70 \%$ of TCE and PCE reacting with $\mathrm{OH}$ produces phosgene $\left(\mathrm{COCl}_{2}\right)$ under atmospheric conditions. $\mathrm{COCl}_{2}$ has negligible reactivity with gas-phase species in the troposphere and a 1.85 year lifetime against photolysis in the stratosphere (Kindler et al., 1995), suggesting that it could transport significant $\mathrm{Cl}$ from TCE or PCE to the stratosphere. However, $\mathrm{COCl}_{2}$ hydrolyzes in liquid water (Sander et al., 2006, and references therein) so that this oxidation product could reduce total gas-phase $\mathrm{Cl}$ perturbations resulting from TCE or PCE. An additional TCE and PCE oxidation product likely to be produced by the mechanisms presented in Nolan et al. (2006) is hydrogen chloride ( $\mathrm{HCl})$, which is soluble in liquid water and readily adsorbed on ice. While $\mathrm{HCl}$ yield is not quantified in the Nolan et al. study, $\mathrm{HCl}$ removal by wet deposition would reduce the total $\mathrm{Cl}$ input to the atmosphere from TCE or PCE emissions. If this effect applies beyond the existing MOZART-3 wet deposition of $\mathrm{HCl}, \mathrm{HOCl}$, and $\mathrm{ClONO}_{2}$ produced in the model troposphere by $\mathrm{Cl}$ released from these compounds, TCE and PCE ODPs reported in this study would be overestimated because of the possible production of $\mathrm{HCl}$ and $\mathrm{COCl}_{2}$ by tropospheric degradation, each of which is subject to wet deposition.

\subsection{ODP uncertainties}

Our study incorporates the VSLSs nPB, PCE, and TCE into a global 3-D CTM that fully represents the upper atmosphere and includes a more comprehensive representation of atmospheric chemistry and transport relevant to the expected effects of these VSLSs than in past studies of nPB. However, the nPB ODPs reported in this study are considerably lower than those in Wuebbles et al. (2001), and the decrease in $\mathrm{BrAc}$ lifetime is not likely to have caused such a large reduction in ODPs. The apparent lower sensitivity of $\mathrm{O}_{3}$ in MOZART-3 to $\mathrm{Br}_{\mathrm{y}}$ from nPB compared to that of $\mathrm{O}_{3}$ in the combination of MOZART-2 with our two-dimensional chemical-transport model (2-D CTM) could arise from several differences in these models, including:

- MOZART-3 uses the JPL02 chemistry recommendation (Sander et al., 2003); MOZART-2 and our 2-D CTM used the prior version.

- Transport in the full-atmosphere MOZART-3 has been revised compared to the tropospheric model, MOZART2 , in tropospheric and stratospheric circulation and in exchange across the tropopause.

- Faster rainfall rates may be obtained in MOZART-3 than in MOZART-2 or the 2-D CTM, leading to faster $\mathrm{Br}_{\mathrm{y}}$ wet deposition.

We did not save information regarding $\mathrm{Br}_{\mathrm{y}}$ wet deposition in our MOZART-3 runs, so that we cannot definitely identify the possible contribution of faster rainout to the lower ODPs obtained for nPB in this study with our existing output.

The lifting speed of VSLSs such as nPB, TCE, and PCE by the MOZART-3 convection process is an important component of their predicted effects on $\mathrm{O}_{3}$. The convective lifting speed is difficult to evaluate against measurements because wind information must be obtained at considerable detail that is unwieldy to use in a model. However, the convection parameterization in WACCM $1 \mathrm{~b}$ must be reasonable in order to allow it to obtain a good representation of temperature and of specific humidity. Because MOZART-3 uses similar convection, we believe it to be reasonable as well with the caveat that it has not been fully evaluated.

MOZART-3, as with other atmospheric models of its generation, uses a somewhat coarse vertical resolution near the tropopause of just under $1 \mathrm{~km}$. This coarse vertical resolution causes MOZART-3 to underestimate steep gradients in the tropopause region (Pan et al., 2007) and could cause an overestimation of the amount of VSLSs that reaches the stratosphere. If this is taking place for nPB, TCE, or PCE, the ODPs reported in this study would be overestimated.

Transport in newer models, including climate-chemistry models such as version 3 of WACCM, is being evaluated against measurements in more detail than was applied to MOZART-3 or WACCM 1b (Gettelman et al., 2010; Neu et al., 2010). In these tests, WACCM 3 was one of the best of the climate-chemistry models in representing transport. While WACCM 3 does include updated processes compared to WACCM $1 \mathrm{~b}$, the earlier version of WACCM, and thus 
MOZART-3 when driven with its meteorology, is likely to have represented atmospheric processing of VSLSs as well as any model of their generation. Transport is nonetheless likely to be one of the most significant components of uncertainty in the ODPs derived in this study, and those values should be taken as uncertain by at least $10 \%$ to $25 \%$.

\section{Summary}

We have calculated atmospheric lifetimes and Ozone Depletion Potentials (ODPs) for the currently-used compounds trichloroethylene (TCE) and perchloroethylene (PCE) and the proposed replacement compound n-propyl bromide (nPB) in the MOZART-3 chemical-transport model of the global atmosphere. Unlike previous studies of nPB in particular, MOZART-3 represents the upper atmosphere fully and includes detailed chemical and transport processes, which leads to a more comprehensive prediction of the effects on ozone to be expected from these gases. For emissions of nPB from all land surfaces between $30^{\circ} \mathrm{N}$ and $60^{\circ} \mathrm{N}$, we obtain a lifetime of 24.7 days and an ODP of 0.0049. Emissions of $\mathrm{nPB}$ from all land between $60^{\circ} \mathrm{S}$ and $70^{\circ} \mathrm{N}$ result in a lifetime of 19.6 days and an ODP of 0.011. These are among the lowest ODPs obtained for a compound containing bromine in our studies so far, and the nPB ODP is lower than obtained in past studies. For PCE emissions from all land surfaces between $30^{\circ} \mathrm{N}$ and $60^{\circ} \mathrm{N}$, the atmospheric lifetime is 111 days and the ODP is 0.0050 , and for TCE emissions from land from $30^{\circ} \mathrm{N}$ to $60^{\circ} \mathrm{N}$, the lifetime is 13.0 days and the ODP is 0.00037 . Neither nPB nor TCE are predicted to reach the stratosphere in large quantity to release bromine or chlorine directly, but significant PCE does reach the stratosphere intact to release chlorine.

Acknowledgements. This research was supported in part by the Albemarle Corporation, by Enviro Tech International, Inc. and by the US Environmental Protection Agency. The views expressed are those of the authors and need not reflect those of the sponsoring organizations. We thank Michael Danilin of Boeing Company for his help in discovering erroneous ODP calculations in an earlier manuscript of this article, and we thank James Franklin and three anonymous referees for their comments. The authors gratefully acknowledge the financial support given by the US Department of Energy, Global Change Education Program-Graduate Research Environmental Fellowship to Mónica Martínez-Avilés.

Edited by: P. Haynes

\section{References}

Atkinson, R., Baulch, D. L., Cox, R. A., Crowley, J. N., Hampson, R. F., Hynes, R. G., Jenkin, M. E., Rossi, M. J., and Troe, J.: Evaluated kinetic and photochemical data for atmospheric chemistry: Volume IV - gas phase reactions of organic halogen species, Atmos. Chem. Phys., 8, 4141-4496, doi:10.5194/acp-84141-2008, 2008.

Bridgeman, C. H., Pyle, J. A., and Shallcross, D. E.: A threedimensional model calculation of the ozone depletion potential of 1-bromopropane (1- $\left.\mathrm{C}_{3} \mathrm{H}_{7} \mathrm{Br}\right)$, J. Geophys. Res., 105, 26493 26502, 2000.

Burkholder, J. B., Gilles, M. K., Gierczak, T., and Ravishankara, A. R.: The atmospheric degradation of 1-bromopropane $\left(\mathrm{CH}_{3} \mathrm{CH}_{2} \mathrm{CH}_{2} \mathrm{Br}\right)$ : The chemistry of bromoacetone, Geophys. Res. Lett., 29, 1822-1825, doi:10.1029/2002GL014712, 2002.

Gettelman, A., Hegglin, M. I., Son, S.-W., Fujiwara, M., Tilmes, S., Pan, L., Hoor, P., Lee, H., Manney, G. L., Birner, T., Stiller, G., Rex, M., Kremser, S., Wuebbles, D., Walker, K. A., and Anel, J. A.: Upper Troposphere and Lower Stratosphere, Stratospheric Processes And Their Role in Climate (SPARC) Report on the Evaluation of Chemistry-Climate Models, edited by Eyring, V., Shepherd, T. G., and Waugh, D. W., World Meteorological Organization, SPARC Report No. 5, WCRP-132, WMO/TD-No. 1526, chapter 7, 253-304, available online at: http://www.atmosp.physics.utoronto.ca/SPARC, June 2010.

Gilles, M. K., Burkholder, J. B., Gierczak, T., Marshall, P., and Ravishankara, A. R.: Rate coefficient and product branching measurements for the Reaction $\mathrm{OH}+$ Bromopropane from 230 to 360 K, J. Phys. Chem. A, 106, 5358-5366, 2002.

Horowitz, L., Walters, S., Mauzerall, D., Emmons, L., Rasch, P., Granier, C., Tie, X., Lamarque, J.-F., Schultz, M., Tyndall, G., Orlando, J., and Brasseur, G. P.: Global simulation of tropospheric ozone and related tracers: Description and evaluation of MOZART, version 2, J. Geophys. Res., 108, 4784, doi:10.1029/2002JD002853, 2003.

Keene, W. C., Khalil, M. A. K., Erickson III, D. J., McCulloch, A., Graedel, T. E., Lobert, J. M., Aucott, M. L., Gong, S. L., Harper, D. B., Kleiman, G., Midgley, P., Moore, R. M., Seuzaret, C., Sturges, W. T., Benkovitz, C. M., Koropalov, V., Barrie, L., A., and Li, Y. F.: Composite global emissions of reactive chlorine from anthropogenic and natural sources: Reactive Chlorine Emissions Inventory, J. Geophys. Res., 104, 8429-8440, 1999.

Kindler, T. P., Chameides, W. L., Wine, P. H., Cunnold, D. M., Alyea, F. N., and Franklin, J. A.: The fate of atmospheric phosgene and the stratospheric loadings of its parent compounds: $\mathrm{CCl}_{4}, \mathrm{C}_{2} \mathrm{Cl}_{4}, \mathrm{C}_{2} \mathrm{HCl}_{3}, \mathrm{CH}_{3} \mathrm{CCl}_{3}$, and $\mathrm{CHCl}_{3}$, J. Geophys. Res., 100, 1235-1251, 1995.

Kinnison, D. E., Brasseur, G. P., Walters, S., Garcia, R. R., Marsh, D. R., Sassi, F., Harvey, V. L., Randall, C. E., Emmons, L., Lamarque, J.-F., Hess, P., Orlando, J. J., Tie, X. X., Randel, W., Pan, L. L., Gettelman, A., Granier, C., Diehl, T., Niemeier, U., and Simmons, A. J.: Sensitivity of chemical tracers to meteorological parameters in the MOZART-3 Chemical Transport Model, J. Geophys. Res., 112, D20302, doi:10.1029/2006JD007879, 2007.

Ko, M. K. W., Poulet, G., Blake, D. R., Boucher, O., Burkholder, J. H., Chin, M., Cox, R. A., George, C., Graf, H.-F., Holton, J. R., Jacob, D. J., Law, K. S., Lawrence, M. G., Midgley, P. M., Seakins, P. W., Shallcross, D. E., Strahan, S. E., Wuebbles, D. J., 
Yokouchi, Y., and contributors: Very Short-Lived Halogen and Sulfur Substances, Scientific Assessment of Ozone Depletion: 2002, World Meteorological Organization Global Ozone Research and Monitoring Project - Report No. 47, Geneva, Switzerland, 2.1-2.57, 2003.

Law, K. S., Sturges, W. T., Blake, D. R., Blake, N. J., Burkholder, J. B., Butler, J. H., Cox, R. A., Haynes, P. H., Ko, M. K. W., Kreher, K., Mari, C., Pfeilsticker, K., Plane, J. M. C., Salawitch, R. J., Schiller, C., Sinnhuber, B.-M., von Glasow, R., Warwick, N. J., Wuebbles, D. J., Yvon-Lewis, S. A., and contributors: Halogenated Very Short-Lived Substances, Scientific Assessment of Ozone Depletion: 2006, WMO (World Meteorological Organization) Global Ozone Research and Monitoring Project - Report No. 50, Geneva, Switzerland, 2.1-2.57, 2007.

Martínez-Avilés, M., Rosado-Reyes, C. M., and Francisco, J. S.: Hydroxyl-radical-initiated oxidation mechanism of bromopropane, J. Phys. Chem. A, 112, 7930-7938, doi:10.1021/jp8034506, 2008a.

Martínez-Avilés, M., Yang, S., and Francisco, J. S.: Structure and vibrational spectra of bromine reservoir species from the atmospheric oxidations of bromoethane and bromopropane, Mol. Phys., 106, 2299-2314, doi:10.1080/00268970701798929, 2008b.

McCulloch, A., Aucott, M. L., Graedel, T. E.., Kleiman, G., Midgley, P. M., and Li, Y.-F.: Industrial emissions of trichloroethene, tetrachloroethene, and dichloromethane: Reactive Chlorine Emissions Inventory, J. Geophys. Res., 104, 8417-8427, 1999.

Neu, J., Strahan, S., Braesicke, P., Douglass, A., Huck, P., Oman, L., Pendlebury, D., and Tegtmeier, S.: Transport, Stratospheric Processes And Their Role in Climate (SPARC) Report on the Evaluation of Chemistry-Climate Models, edited by Eyring, V., Shepherd, T. G., and Waugh, D. W., World Meteorological Organization, SPARC Report No. 5, WCRP-132, WMO/TDNo. 1526, chapter 5, 149-190, available online at: http://www. atmosp.physics.utoronto.ca/SPARC, June 2010.

Nolan, L., Guihur, A.-L., Manning, M., and Sidebottom, H.: Atmospheric oxidation of the chlorinated solvents, 1,1,1Trichloroethane, Trichloroethene and Tetrachloroethene, in Environmental Simulation Chambers: Application to Atmospheric Chemical Processes, edited by: Barnes, I. and Rudzinski, K. J., Springer, The Netherlands, 171-179, doi:10.1007/1-4020-42329, 2006.

Office of Environmental Health Hazard Assessment (OEHHA): Acute Toxicity Summary: Perchloroethylene, State of California (USA) OEHHA, 5 pp., available online at: http://oehha.ca.gov/ air/acute_rels/pdf/127184A.pdf, last access: 20 July 2010, 1999.

Office of Environmental Health Hazard Assessment (OEHHA): Chronic Toxicity Summary: Trichloroethylene, State of California (USA) OEHHA, 8 pp., available online at: http://oehha. ca.gov/air/chronic_rels/pdf/79016.pdf, last access: 20 July 2010, 2000.

Olsen, S. C., Hannegan, B. J., Zhu, X., and Prather, M. J.: Evaluating ozone depletion from very short-lived halocarbons, Geophys. Res. Lett., 27, 1475-1478, 2000.
Pan, L. L., Wei, J. C., Kinnison, D. E., Garcia, R. R., Wuebbles, D. J., and Brasseur, G. P.: A set of diagnostics for evaluating chemistry-climate models in the extratropical tropopause region, J. Geophys. Res., 112, D09316, doi:10.1029/2006JD007792, 2007.

Sander, S. P., Friedl, R. R., Golden, D. M., Kurylo, M. J., Huie, R. E., Orkin, V. L., Moortgat, G. K., Ravishankara, A. R., Kolb, C. E., Molina, M. J., and Finlayson-Pitts, B. J.: Chemical Kinetics and Photochemical Data for Use in Atmospheric Studies. NASA/JPL Data Evaluation, JPL Publication 02-25 Evaluation No. 14, NASA, Pasadena, California, USA, available online at: http://jpldataeval.jpl.nasa.gov/, 2003.

Sander, S. P., Friedl, R. R., Golden, D. M., Kurylo, M. J., Moortgat, G. K., Keller-Rudek, H., Wine, P. H., Ravishankara, A. R., Kolb, C. E., Molina, M. J., Finlayson-Pitts, B. J., Huie, R. E., and Orkin, V. L.: Chemical Kinetics and Photochemical Data for Use in Atmospheric Studies, Evaluation Number 15, JPL Publication 06-2, NASA Panel for Data Evaluation, Jet Propulsion Laboratory, California Institute of Technology, Pasadena, California, USA, available online at: http://jpldataeval.jpl.nasa.gov/, 2006.

Sassi, F., Kinnison, D., Boville, B. A., Garcia, R. R., and Roble, R.: Effect of El Niño-Southern Oscillation on the dynamical, thermal, and chemical structure of the middle atmosphere, J. Geophys. Res., 109, D17108, doi:10.1029/2003JD004434, 2004.

Solomon, S., Mills, M., Heidt, L. E., Pollock, W. H., and Tuck, A. F.: On the evaluation of ozone depletion potentials, J. Geophys. Res., 97, 824-842, 1992.

Wei, C.-F., Kotamarthi, V. R., Ogunsola, O. J., Horowitz, L. W., Walters, S., Wuebbles, D. J.., Avery, M. A., Blake, D. R., Browell, E. V., and Sachse, G. W.: Seasonal variability of ozone mixing ratios and budgets in the tropical southern Pacific: A GCTM perspective, J. Geophys. Res., 107, 8235, doi:10.1029/2001JD000772, 2003.

Wuebbles, D. J.: The Relative Efficiency of a Number of Halocarbons for Destroying Ozone, Lawrence Livermore National Laboratory Report UCID-18924, Livermore, California, USA, 11 pp., 1981.

Wuebbles, D. J.: Chlorocarbon emission scenarios: potential impact on stratospheric ozone, J. Geophys. Res., 88, 1433-1443, 1983.

Wuebbles, D. J., and Ko, M. K. W.: Summary of EPA/NASA Workshop on the Stratospheric Impacts of Short-Lived Gases, 30-31 March, Washington, D.C., available through the US Environmental Protection Agency, Stratospheric Protection Division, Washington, DC, USA, 1999.

Wuebbles, D. J., Kotamarthi, R., and Patten, K. O.: Updated evaluation of Ozone Depletion Potentials for Chlorobromomethane $\left(\mathrm{CH}_{2} \mathrm{ClBr}\right)$ and 1-bromo-propane $\left(\mathrm{CH}_{2} \mathrm{BrCH}_{2} \mathrm{CH}_{3}\right)$, Atmos. Environ., 33, 1641-1643, 1999.

Wuebbles, D. J., Patten, K. O., Johnson, M. T., and Kotamarthi, R.: New methodology for Ozone Depletion Potentials of short-lived compounds: n-Propyl bromide as an example, J. Geophys. Res., 106, 14551-14771, 2001. 